\title{
Recursos semióticos en los anuncios publicitarios sobre discapacidad en la prensa escrita costarricense ${ }^{1}$
}

Por: Dr. Adrián Vergara-Heidke², Universidad de Costa Rica, Costa Rica y

Br. Gina Torres-Calderón ${ }^{3}$, Universidad de Costa Rica, Costa Rica

\section{Resumen}

La investigación presenta el resultado del análisis multimodal de 68 anuncios publicitarios sobre discapacidad que fueron publicados durante el período 2014-2016 en los tres periódicos de mayor difusión en Costa Rica (La Nación, Diario Extra y La Teja). Se recolectaron los anuncios, se catalogaron y se empleó la metodología de Kress y Van Leeuwen $(2001,2002,2006)$ para determinar los modos que se interrelacionan en la construcción de discursos sobre discapacidad. Se establecen los recursos semióticos que se emplean en los anuncios analizados para la caracterización de las personas con discapacidad (PCD). Se concluye que los anuncios crean los significados mediante la interrelación semiótica, es decir, mediante la multimodalidad y para su comprensión total deben valorarse los recursos lingüísticos y paralingüísticos que componen los anuncios. Además, tras el análisis se determina que los anuncios promueven todavía un discurso discriminatorio que se evidencia en la discrepancia del componente icónico del anuncio y del lingüístico, ya que en el primero se le da protagonismo parcialmente a las PCD, mientras que la lingüística demuestra que el protagonismo lo tienen los anunciantes y que las PCD quedan relegadas a roles secundarios.

\section{Semiotics resources in advertisements on disabilities in the Costa Rican print media}

\section{Abstract}

This research shows the results of the multimodal analysis of 68 advertisements on disability published from 2014 to 2016 in the three newspapers of largest circulation in Costa Rica (La Nación, Diario Extra and La Teja). The advertisements

1 Este artículo es parte del proyecto "El discurso sobre la discapacidad en costa Rica: el discurso sobre la discapacidad en ámbitos cotidianos, educativos y políticos", de la Vicerrectoría de Acción Social de la Universidad de Costa Rica.

2 El doctor Adrián Vergara Heidke obtuvo su doctorado en Lingüística en la Universidad de Bremen, Alemania. Labora como profesor de la Escuela de Filología, Lingüística y Literatura de la Universidad de Costa Rica. Contacto: avheidke@gmail.com y adrian.vergara@ucr. ac.cr.

3 Gina Torres Calderón es bachiller en Filología Española y estudiante del posgrado en Lingüística y del Posgrado en Español como Segunda Lengua en la Universidad de Costa Rica. Contacto: yinaf608@gmail.com y gina.torrescalderon@ucr.ac.cr.

Adrián Vergara-Heidke y Gina TorresCalderón. Recursos semióticos en los anuncios publicitarios sobre discapacidad en la prensa escrita costarricense. Revista Comunicación. Año 40 , volumen 28 , número 1 , enero-junio, 2019. Instituto Tecnológico de Costa Rica. ISSN: 0379-3974 / e-ISSN1659-3820.

\section{PALABRAS CLAVE:}

discapacidad, semiótica, publicidad, multimodalidad, análisis multimodal, análisis crítico del discurso

\section{KEY WORDS:}

disability, Semiotic, Advertising, multimodality, Multimodal Advertising, Critical Discourse Analysis. 
were collected, catalogued and analyzed using the theory of multimodality by Kress and Van Leuwen (2001, 2002, 2006) to determine how semiotic modes question the construction of discourses on disability. The semiotic resources used in the ads are established to determine the characterization of people with disabilities. The study concludes that the advertisements create meaning through semiotic interrelation, that is, through multimodality, and the linguistic and paralinguistic resources that compose the advertisements must be valued for them to be fully understood. Furthermore, after the analysis, the study determines that the advertisements continue to promote a discriminatory discourse evidenced by the discrepancy between the iconic component of the advertisement and the linguistic one, since the former gives prominence to the PwD, but the linguistic component shows that advertisers play a predominant role and PwD are relegated to secondary roles.

Las personas con discapacidad o diversidad funcional (PCD, en adelante), términos intercambiables desde nuestra concepción, siguiendo la reflexión terminológica de Ferreira (2008), corresponden al $15 \%$ de las personas en el mundo, unos 85 millones en Latinoamérica, y al 10,5\% en Costa Rica, cuarto país con más prevalencia de PCD en la región, después de Brasil, Nicaragua y Argentina, según el Informe mundial sobre discapacidad (OMS, 2011). A pesar de este alto número de PCD, los estudios al respecto se han desarrollado principalmente en áreas como Educación y Medicina, en las que se ha asentado una perspectiva de clasificación, separación y exclusión; mientras que en otras disciplinas de Humanidades y Ciencias Sociales, la discapacidad ha sido relegada a un estrato casi nulo, tal como lo expone Vergara-Heidke (2018), quien muestra la falta de investigación en Latinoamérica y afirma que "la exclusión y menosprecio que las PCD sufren socialmente se ven reflejados en los pocos trabajos académicos que abordan la discapacidad" (p. 2).

Las investigaciones con énfasis en publicidad y PCD se han desarrollado principalmente desde el análisis de contenidos. El principal trabajo es el de Cebrián (2010), quien analiza la percepción de la imagen de las PCD por parte de los profesionales de los medios de comunicación y, mediante el análisis de campañas, determina cómo son representadas estas personas en el cine, en la televisión y en la publicidad. Concluye el autor que los temas con los que se han relacionado históricamente la discapacidad en la publicidad son la salud, la vida, la seguridad y el placer, y agrega que estos no son temas excluyentes en un mismo anuncio. Además, la discapacidad se presenta en estas temáticas desde una perspectiva negativa, por lo que afirma que hay una construcción peyorativa del discurso de la discapacidad que se caracteriza por la diferencia, la ayuda social y por la pertenencia a un mundo de "lo normal o de lo no-normal" (p. 23). Finalmente, afirma que hay un doble discurso en los medios: uno convencional que busca la integración (normal/anormal, salud/enfermedad) y otro emergente que se basa en la normalización y en la noción de discapacidad como parte posible de la vida diaria de las personas.

Madero (2012), por su parte, analiza la evolución de la publicidad respecto del tratamiento de la discapacidad. Afirma que "la discapacidad está poco y mal representada en los medios de comunicación" $(2012$, p. 7), puesto que no hay una aparición significativa de las PCD en los anuncios publicitarios de las campañas comerciales y de sensibilización que analizó, y porque esta invisibilización crea la idea de que no existe la discapacidad y de que las PCD no son parte de la sociedad. Aunado a lo anterior, cuando aparecen PCD en los anuncios, normalmente no se les da la palabra o no aparecen haciendo actividades por sí mismas, sino que reciben acciones de otros.

En los estudios desde la multimodalidad y el análisis del discurso la constante ha sido la escasez y los trabajos hechos han tenido un énfasis educativo, 
principalmente. Tal es el caso de las investigaciones de Manghi, Arancibia, Illanes, Letelier y Zamora (2014) en los que se describen los recursos empleados en una clase para personas con alguna discapacidad y el potencial semiótico de los recursos en la enseñanza, y concuerdan los autores en que la simultaneidad en el uso de los recursos semióticos hace que se pondere la interacción multimodal en las clases. Por su parte, Fernández (2016) determina los procesos de subalternización en el ámbito educativo de Costa Rica y afirma que la valoración de las PCD dentro de la sociedad está en una relación dialéctica del desempeño y el trabajo.

En la revisión bibliográfica hecha, solamente el artículo de Vergara-Hilke (2018) no se relaciona con la educación. Este autor, a partir del análisis con grupos de discusión con padres de PCD y observa las valoraciones negativas -incluye las categorías del menosprecio, la dependencia y la condición de salud- como elementos determinantes de "la discapacidad". Concluye que la repetición del discurso de discapacidad cargado de valoraciones negativas, de dependencia, de menosprecio y relacionado directamente con condiciones de salud, dificultan el logro de la inclusión social de las PCD.

Considerando que existe poco abordaje y un creciente interés multidisciplinario en el tema de la discapacidad, se plantea la necesidad de analizar el discurso publicitario con el fin de determinar los recursos semióticos utilizados para la caracterización de las PCD en los anuncios publicitarios en la prensa escrita costarricense, del 2014 al 2016.

\section{FUNDAMENTOS TEÓRICOS}

\section{Análisis multimodal}

En el marco de la semiótica social y en la premisa multisemiótica de la mayor parte de los textos de la actualidad (Jäger, 2003; Fairclough y Wodak, 2008), el enfoque multimodal explora métodos de análisis en los que se pone "más atención que la lingüística crítica a las prácticas de producción e interpretación relacionadas con distintos tipos de textos y con los textos per se" (Fairclough y Wodak, 2008, p. 375). Con base en la semiótica social y del análisis crítico del discurso, Kress y Van Leeuwen (2001) proporcionan los fundamentos del análisis multimodal (también enfoque multimodal, análisis del discurso multimodal), el cual se ocupa de la teoría y del análisis de los recursos semióticos y de las expansiones semánticas que tienen lugar a medida que se combinan las diferentes opciones semióticas disponibles en los textos multimodales.

Algunos intereses del análisis multimodal del discurso son las relaciones 'inter-semióticas' (o intermodales) que surgen a partir de la interacción de las opciones semióticas, conocidas como intersemiosis. Según Jewitt (2009), el análisis multimodal "se ocupa del diseño, de la producción y de distribución de los recursos multimodales en contextos sociales" (p. 77) y de la construcción y relación de sentidos mediante el uso de modos o recursos semióticos en los textos (O'Halloran, 2012).

Para Kress y Van Leeuwen (2001), las construcciones de sentidos se producen, primeramente, mediante la multimodalidad, que es definida "como el uso de varios modos semióticos en el diseño de un evento o producto semiótico, así como la forma particular en la que estos modos se combinan" (p. 20) y puede verse como un modelo de significación intersemiótica que conceptualiza la práctica de los procesos de significación que emplean las personas en la comunicación. En segundo lugar, ubicados dentro del estrato del contenido, los discursos son "formas socialmente situadas de conocimiento sobre (aspecto de) la realidad" (ídem, p. 20), conocimientos construidos socialmente, ya sea a nivel familiar o continental, que se transmiten con la intención de propagar el significado de eventos, lugares, actos, situaciones, entre otros. Tomando en cuenta las propuestas de Jäger (2003), Wodak y Meyer (2003), Vergara-Heike (2018) y Vergara-Heidke y Torres-Calderón (2019), entendemos el discurso como un conocimiento compartido por un grupo, una construcción social considerada verdadera en términos de ser aceptada, que sirve para el ordenamiento del mundo, la regulación de los acciones y la forma de pensar que tienen sobre eventos, situaciones, pensamientos o lugares las personas que pertenecen al grupo y que se reproduce mediante los medios de comunicación y por vías orales oficiales y no oficiales. 
Un segundo estrato dentro del contenido es el diseño, que Kress y Van Leeuwen (2001) lo definen de la siguiente manera:

Conceptualizaciones de las formas de los productos o eventos semióticos. Hay tres cosas que se diseñan simultáneamente: (1) la formulación de un discurso o las combinaciones de discursos, (2) la (inter)acción particular, en la que el discurso se inserta, y (3) la forma particular de combinar los modos semióticos (p. 21),

por lo que echan mano de los modos para establecer las relaciones sociales que se pretenden comunicar mediante el texto.

Otros dos estratos que se representan en la expresión son la producción, "la organización de la expresión, a la articulación material real del evento semiótico o a la producción material real del artefacto semiótico" (Kress y Van Leeuwen, 2001, p. 5), y la distribución, que se identifica como el orden de los elementos que configuran un evento semiótico, a la recodificación técnica.

\section{Recursos semióticos o modos}

Los modos son "recursos semióticos que permiten la realización simultánea de discursos y tipos de (inter)acción" (Kress y Van Leeuwen, 2001, p. 21), recursos social y culturalmente formados, motivados y establecidos para dar sentido (Kress, 2009) por un grupo $y$, aunque son producidos por un "signmaker", tienen un valor propio en sus entornos culturales, lo que implica que tienen un impacto social mediado por los propósitos de su creación y a la regularidad de su uso en la vida social, es decir, "lo que hace de un modo un modo es su disponibilidad como recurso para producir signos en un grupo socio-cultural" (Kress y Van Leeuwen, 2001, p. 3).

Algunos modos tienen funciones, tal como se observa en la Figura 1:

\section{Figura 1. Modos y funciones}

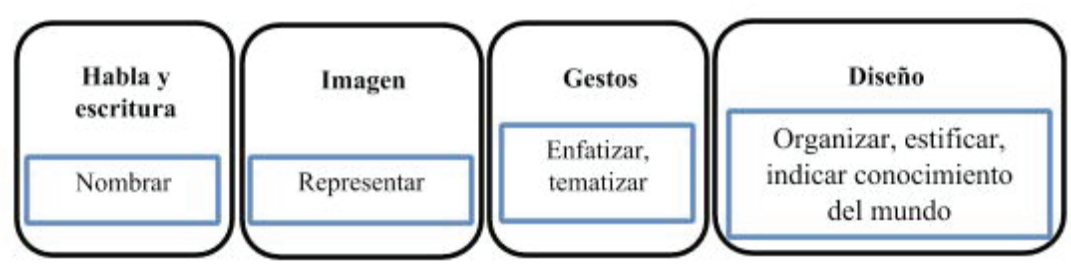

Fuente: Elaboración propia, con base en Kress (2009, p. 64)

Aunque se ha intentado resumir la función de algunos modos, precisa agregar que es imposible dar una lista de los modos existentes en una comunidad de habla, principalmente, porque la variedad de los modos depende de la sociedad, ya que un modo es "lo que una comunidad decide recordar, presentar y usar como un modo" (Kress, 2010, p. 87), siempre con su disposición funcional y formal. A pesar de la dificultad, a continuación se exponen algunos modos fundamentales para el análisis de los anuncios publicitarios.

\subsection{Color}

El color es considerado por Kress y Van Leeuwen (2002) el modo más complejo por su multifuncionalidad. Mediante el color se puede identificar, mostrar filiación, asociación, proveniencia, dar Cohesión y, destaca en el texto, la posibilidad de realizar las tres metafunciones propuestas por Halliday (2014), tal como se muestra en la Tabla 1. 
Tabla 1

Metafunciones y funciones del color

\begin{tabular}{|l|l|}
\hline Metafunción del lenguaje & \multicolumn{1}{c|}{ Función del modo } \\
\hline Ideativa & denotar personas, lugares y cosas, clases de personas \\
\hline Interpersonal & actos de color: impresionar, advertir, intimidar, mandar mensajes \\
\hline Textual & $\begin{array}{l}\text { mostrar diferencias entre un conjunto de elementos, dar coherencia- } \\
\text { identificar grupos de semejantes }\end{array}$ \\
\hline
\end{tabular}

Fuente: Elaboración propia según Kress y Van Leeuwen (2001, 2002, 2006).

La última función es preciso ampliarla e indicar que el color cumple una función textual pues permite dilucidar las diferencias entre edificios, sillas, por ejemplo, o, por el contrario, crear unidad y coherencia en los edificios de un residencial, y esto da coherencia en los textos, ya que al dar el mantenimiento de un color o una coordinación de colores, un grupo se identifica como parte de un texto mayor. Esta coherencia textual de los colores se puede llamar "esquemas de color".

\subsection{Enmarcado}

El enmarcado -framing- se refiere a la forma en que los elementos de una composición visual se "encierran" mediante líneas marcadas, elementos de marco pictórico (límites formados por la arista de un edificio, un árbol, etc.), el espacio vacío entre los elementos, las discontinuidades de color, entre otras (Kress, 2009). Según Kress y Van Leeuwen (2001), cuanto más fuerte sea el enmarcado de un elemento, más se destaca su presencia como una unidad de información separada. Asimismo, según Fairclough (2003), este da "cuando la voz de otro se incorpora en un texto, siempre hay decisiones sobre cómo "enmarcarla", cómo contextualizarla, en relación con otras partes del texto (p. 53) y con las otras voces que componen el texto, por lo que no es lo mismo incluir un comentario mediante el estilo indirecto que usando el estilo directo, por ejemplo, todo esto está permeado por los roles sociales de cada participante.

\subsection{Encuadre}

Además de las acepciones anteriores para framing, es preciso hacer la salvedad de que en Fairclough (2003) y en O'Halloran (2012) también se utiliza para hablar del enfoque que se hace al tomar una fotografía con el fin de destacar un aspecto de un texto en un plano específico, del ángulo de la cámara y de los movimientos, en el caso de vídeos, por lo que esto no debe considerarse dentro del modo "enmarcado". En este caso, consideramos más apropiado hablar de "encuadre" para evitar confusiones terminológicas en español y seguimos la propuesta presente en $\mathrm{O}^{\prime}$ Halloran (2012, p. 86) sobre la composición el ángulo o perspectiva de la fotografía (HP, VP, POV) y sobre la distancia tomada para la fotografía (close-up, extreme close-up, extreme long short, entre otros).

\section{Representación de actores sociales}

Como se anotó anteriormente, la teoría de las funciones del lenguaje fue desarrollada en un principio por Halliday (1979) con su propuesta de función ideativa, interpersonal y textual. No obstante, al profundizar en la representación de los actores sociales, Fairclough (2003) considera las anteriores funciones, amplía la percepción sobre el acto comunicativo y propone que se debe entender que las funciones son: la representación, que corresponde a la función ideativa de Halliday; acción, cuyo referente sería la función interpersonal -aunque la propuesta de Fairclough hace más énfasis en los textos como formas de (inter)actuar en eventos sociales-, y la identificación, relacionada parcialmente con la función textual, pues sirve para dar cohesión a los textos. Valga decir que Fairclough (2003) afirma que "nosotros podemos ver acción, representación e identificación simultáneamente a través de un texto completo o en parte de los textos" (p. 27).

También, para Fairclough (2003), los textos y los agentes sociales no son agentes "libres", sino que están determinados socialmente, pero sus acciones no lo están. "Los agentes tienen sus propios 'poderes causales' que no son reducibles a los poderes 
causales de las estructuras y prácticas sociales (...). Los agentes sociales texturizan los textos, establecen las relaciones entre los elementos de los textos" (p. 22), por lo que se pueden analizar al abordar un texto. Por ejemplo, afirma Fairclough (2003) que los actores sociales "participan en procesos sociales", en las cláusulas son participantes o circunstancias, tienen rasgos contextuales (género, edad, profesión, entre otros) y aspectos sociocognitivos (identidad, filiación de grupo, creencias, estereotipos, entre otros), por lo que la representación de los actores sociales tiene un significado social y su representación en los textos no es fortuita.

Además, al analizar un texto, según Fairclough (2003), es posible determinar si la representación de los actores sociales evidencia que se suprimen, se excluyen o se incluyen, así como las estrategias por las cuales se hace, tal como se resume en la Tabla 2. Esta interpretación y definición de los actores sociales mantienen las bases foucaultianas sobre el poder simbólico como control.

Tabla 2

Representación de los actores sociales

\begin{tabular}{|l|l|}
\hline \multirow{5}{*}{ Exclusión } & Supresión: no se mencionan del todo en el texto \\
\cline { 2 - 3 } & $\begin{array}{l}\text { Backgrounding: se menciona en alguna parte del texto, pero tiene que ser inferido en otras } \\
\text { partes. }\end{array}$ \\
\hline \multirow{5}{*}{ Inclusión } & Pronombre/nombre: cuando el actor social mostrado mediante un pronombre o un nombre \\
\cline { 2 - 3 } & $\begin{array}{l}\text { Rol gramatical: si el actor social tiene un rol de participante, circunstancia o nombre posesivo } \\
\text { o pronombre dentro de una cláusula. }\end{array}$ \\
\cline { 2 - 3 } & $\begin{array}{l}\text { Activo/pasivo: si el actor social realiza la acción o la recibe, es el afecto o el beneficiario. } \\
\text { Personal/impersonal: los actores sociales pueden representarse ya sea personalmente o imper- } \\
\text { sonalmente (abstracciones). }\end{array}$ \\
\cline { 2 - 3 } & $\begin{array}{l}\text { Nombrado/clasificado: los actores sociales pueden aparecer con un nombre o en términos de } \\
\text { clase o categoría (p. e. el doctor) o términos generales (los doctores). }\end{array}$ \\
\cline { 2 - 3 } & $\begin{array}{l}\text { Específico/genérico: donde los actores sociales son clasificados, pueden representarse especí- } \\
\text { ficamente o genéricamente (todos los que pertenecen a un grupo). }\end{array}$ \\
\hline
\end{tabular}

Fuente: Elaboración propia, según Fairclough (2003, pp. 145-146).

Cabe decir que esta representación puede visualizarse tanto en imágenes como a nivel textual, por lo que el análisis es posible hacerlo en ambos modos de los textos. Además, es pertinente agregar que algunas de las categorías dicotómicas pueden ser analizadas gradualmente, ya que tanto textual como visualmente la función de los personajes puede tener, por ejemplo, un rol pasivo recibidor o pasivo circunstancial, por lo que hemos decidido analizar el rol de los personajes según las categorías de exclusión e inclusión de Fairclough (2003) y en vez de una dicotomía "activo/pasivo", consideramos que es necesario clasificar las acciones en activo, pasivo, estativo y recibidor.

\section{Discursos sobre discapacidad}

Al tratar de definir en qué consiste la discapacidad, López (2006) afirma que el hecho mismo de utilizar esta palabra "implica una matización lingüística que responde a un determinado posicionamiento conceptual" (p. 1). Consideramos que es necesario ampliar esta idea y plantear que es un acto de posicionamiento ideológico con concepciones predeterminadas sobre la persona en general y sobre los estereotipos de belleza, de normalidad y de funcionamiento en sociedad, es "el conocimiento sobre discapacidad que se comparte dentro de un grupo social y que guía sus actos sociales e interpretaciones" (Vergara-Heidke, 2018, p. 5), que ha pasado de la consideración de problema a la de hacinamiento, de enfermedad, hasta la actualidad, que busca ser de inclusión. 
Como fundamento de nuestra posición, es preciso mencionar que Gimeno (2008) apunta que el discurso de la discapacidad se caracteriza por la "opresión y discriminación" (p. 1). Asimismo, tal como lo expone Vergara-Heidke (2018), este discurso es "el conocimiento sobre discapacidad que se comparte dentro de un grupo social y que guía sus actos sociales e interpretaciones" (p. 5), es decir, no se limita a lo verbal, sino que abarca lo mental, social, comunicativo y no comunicativo. Además, Corker (2008) y Peters (2008) afirman que el discurso de la discapacidad se configura mediante la relación con la cultura de la discapacidad que abarca tanto lo personal, íntimo, familiar como lo público, por lo que en la existencia de una cosmovisión, la perspectiva histórico-lingüística es fundamental, ya que se presenta como una "cosmovisión sincrética" en la que "la cultura de la discapacidad existe sin importar si yo manifiesto o no 'soy discapacitada' o si me identifico con una comunidad de personas con discapacidad" (Peters, 2008, p. 161).

Considerando lo anterior, se puede decir que el discurso de la discapacidad conlleva un proceso cultural expreso en las personas y en las formas de comunicación; es un posicionamiento ideológico respecto de una serie de aseveraciones sobre la discapacidad que se vincula con parámetros impuestos por la sociedad respecto de la belleza, la normalidad y la producción, entre otros, que se proyectan en las PCD y se muestran en los contextos en los que se desenvuelven, en las acciones que desarrollan y en las formas en las que se les representa socialmente.

Así las cosas, al profundizar en los discursos de discapacidad hay que decir que los autores consultados exponen varias clasificaciones, no obstante, consideramos que lo más apropiado es hablar de tres discursos más comunes y un cuarto que se encuentra en un estado emergente (López, 2006; Palacios, 2008; Francisco, 2003; Cebrián, 2010; Toboso-Marín, 2013; Victoria, 2013; Vergara-Heidke, 2018; Vergara-Heidke y Torres-Calderón, 2019).

\section{MARCO METODOLÓGICO}

Con base en los lineamientos metodológicos del análisis multimodal expuestos en Kress y Van
Leeuwen $(2001,2002,2006)$ y Kress $(2009,2010$, 2012), en el presente trabajo se aplicó un análisis multimodal a un total de 68 anuncios publicitarios sobre discapacidad que se pautaron en los periódicos costarricenses La Nación, La Extra y La Teja, principales periódicos de la prensa escrita de Costa Rica, tanto por su difusión como por la variedad de lectores meta.

Para el análisis se revisaron todos los anuncios publicados en los periódicos durante el 2014, 2015 y 2016, se contabilizaron tanto aquellos que tenían relación con discapacidad como los que no la tenían. Seguidamente, se registraron los anuncios que cumplieran con los criterios de selección: el uso de algún término relacionado con la discapacidad/ diversidad funcional o que mostrara a una persona con alguna condición discapacitante. Luego, se identificó la fecha, el tamaño de los anuncios y el periódico de publicación. Para cada anuncio analizable se estableció un criterio de registro según las iniciales del periódico de aparición (LN, DE o LT), la fecha de publicación (ej.: 29022014) y la página (94A).

Tomando en consideración nuestra posición sobre los modos, tal como se expuso anteriormente, los 68 anuncios publicitarios que tienen relación con discapacidad o diversidad funcional se analizaron multimodalmente para determinar cuáles son los recursos semióticos empleados, cuáles son las funciones de cada modo y cómo se interrelacionan estos para construcción de los discursos sobre discapacidad. Es importante notar que se parte de la idea del objetivo persuasivo de la publicidad, por lo que se considera que los modos son empleados para evidenciar el objetivo, y que hay un proceso de creación motivado (Adam y Bonhomme, 2000).

Finalmente, con base en la propuesta de Fairclough (2003) sobre los actores sociales y la teoría de la multimodalidad de Kress y Van Leeuwen (2001, 2006) sobre los recursos semióticos, se identificó la forma de representación de las personas con discapacidad en los anuncios publicitarios y los recursos semióticos empleados para la configuración del sentido. Para esto, se han establecido las siguientes categorías de análisis: en primer lugar, los personajes del anuncio con énfasis en el protagonista y el 
rol que tienen dichos personajes y, en segundo lugar, la representación de los actores sociales en las categorías de análisis de la relación interpersonal entre participantes del anuncio, la forma de comunicación y la proxémica respectiva.

Respecto de estos discursos, el primero es el de prescindencia o eugenésico, caracterizado por la exclusión de las PCD y su total discriminación socialmente, seguido del médico rehabilitador, cuya base está en la medicina como fuente de definición de "normalidad" y el papel de las PCD dentro de esta categoría (Palacios, 2008 y Victoria, 2013). El tercer discurso es el discurso social, que tiene una base integracionista en el que se rechaza la noción de "castigo divino" y de "enfermedad", presente en los anteriores discursos, y que propone la necesidad de entender la discapacidad desde una perspectiva ecológica-holística, por la relación de la persona con su entorno y con la constitución de barreras sociales.

Desde nuestra perspectiva, es necesario hacer una división entre el mencionado discurso social-integracionista y la perspectiva inclusiva, un cuarto discurso, ya que "la integración nos induce a creer que podemos escoger qué seres humanos tienen derecho a estar en las escuelas, en los parques de diversiones, en las iglesias, en los ambientes de trabajo, en todos los lugares" (Francisco, 2008, p. 19), por lo que nos atrevemos a establecer un cuarto discurso de discapacidad -mencionado por Cebrián (2010) como un movimiento "emergente": el discurso de diversidad funcional. Además, planteamos que su objetivo es la inclusión, es decir, el rechazo a la clasificación y la selección de personas por sus limitaciones, dificultades, la búsqueda del trabajo en las necesidades como algo propio del ser humano.

En términos generales, desde el discurso de diversidad funcional "incluir es la creencia de que todos tienen derecho de participar activamente en la sociedad. Como parte de su ideología, la inclusión viene para derribar las barreras cristalizadas en torno a grupos estigmatizados" (Francisco, 2008, p. 20), de modo que la sociedad atiende las necesidades de todas las minorías y promueve su inserción en todos los ámbitos, sin separación, sin clasifica- ción y sin distinción para atender las necesidades de las minorías.

\section{RESULTADOS}

A continuación, se exponen los principales resultados de la revisión de 42.393 anuncios publicitarios. No obstante, hay que decir que solo 68 de este gran número fueron analizables ya que cumplían los requisitos de selección de la muestra indicados anteriormente. Primeramente se presenta la información según los planteamientos teóricos de Kress y Van Leeuwen (2001, 2010), luego se comentan las relaciones intersemióticas presentes en los anuncios y que constituyen un conjunto semiótico y se concluye con la representación de los actores sociales desde los lineamientos de Fairclough (2003).

\section{Modos}

\subsection{Distribución: posición}

Tal como se ha presentado en el apartado correspondiente, para Kress y Van Leeuwen (2001), un modo es capaz de crear significados, tiene valor sociocultural y puede llegar a ser por sí solo un recurso semántico muy importante para la construcción de sentidos. Lo que se quiere decir con esto es que las personas, conscientes del valor del color, de la tipografía, entre otros modos, emplean estas herramientas para la construcción de discursos que, a su vez, están cargados de mensajes ideológicos; siempre desde una posición social compartida de sentidos.

Concretamente, según el análisis, uno de los estratos de significación de mayor empleo para la construcción de significados es el de la distribución, principalmente el modo de la posición, pero za qué nos referimos con posición? Desde nuestra perspectiva, la presentación de las personas u objetos en una determinada posición o perfil tiene un fin motivado, dentro de las cuales se encuentran establecer líneas de lectura y enfocar elementos del anuncio que resultan vinculantes con la temática de la discapacidad.

En el caso de los anuncios, la posición tiene el objetivo, principalmente, de destacar el beneficiario del anuncio; por ejemplo, en la Figura 2 se observa el 
perfil de la silla de ruedas que se ubica en el plano central, seguido del mensaje "Regale transporte con seguridad y comodidad" y de $\$ 95000$. Según el orden de lectura y por la posición destacada de la silla, la ubicación de la persona con discapacidad en el plano central de lectura tiene un orden jerárquico.
Figura 2

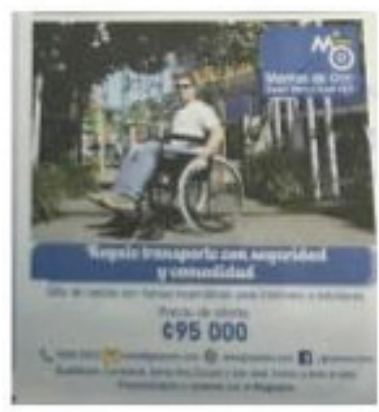

Fuente: LN-080316-P3
Figura 3

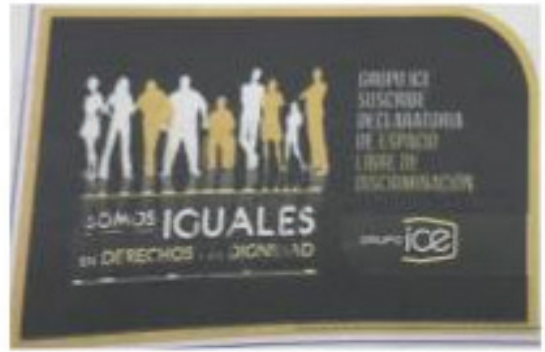

Fuente: DE-291016-P26
Figura 4

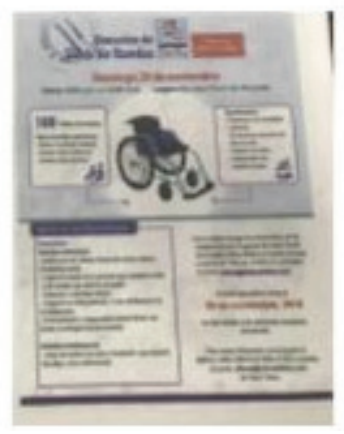

Fuente: DE-01116-P23
En el caso del anuncio en la Figura 3, se presenta la posición central de la persona entre los demás participantes del anuncio y, nuevamente, es una persona en silla de ruedas. Cabe decir que esta combinación de ubicación central en el anuncio y la utilización de una silla de ruedas aparece en el 63\% de los anuncios analizados. Además, cuando se empleó en los anuncios una silla de ruedas, siempre aparecía en una posición central de lectura, ya sea que una persona la usara o que estuviera vacía (Figura 4).

Desde una perspectiva crítica, la posición de las PCD tiene el objetivo de mostrar a la persona beneficiada, por un lado, desde su condición de PCD. Por otro, hay que decir que se resalta aquello que la hace parte de esta población, por lo que se puede afirmar que se recurre a la idea de que las PCD son diferentes y que tienen algo que las marca e identifica, es decir, mediante la posición se les resalta aquello que marca su condición de discapacidad y por lo que son diferentes. La forma en la que se marca la condición discapacitante se produce cuando no aparece una persona, sino que solo hay texto o una silla de ruedas en el anuncio, como la Figura 4.

Para continuar con nuestra afirmación sobre la existencia de prácticas discursivas discriminatoras en los anuncios, es preciso decir que no solo la posición central es determinante para resaltar a la PCD, véase el anuncio de la Figura 12, que se le ubica a la persona en silla de ruedas dentro del grupo "vulnerable", en este caso al lado de la mujer embarazada, y no con las demás personas.
Figura 5

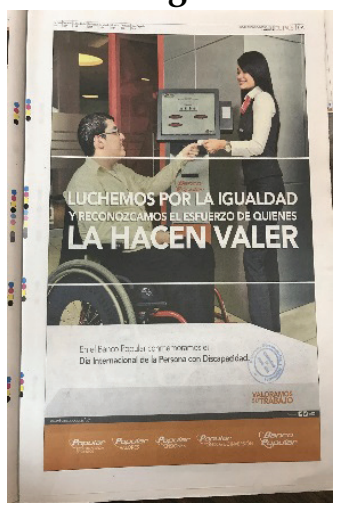

Fuente: LN-290515-P25
Figura 6

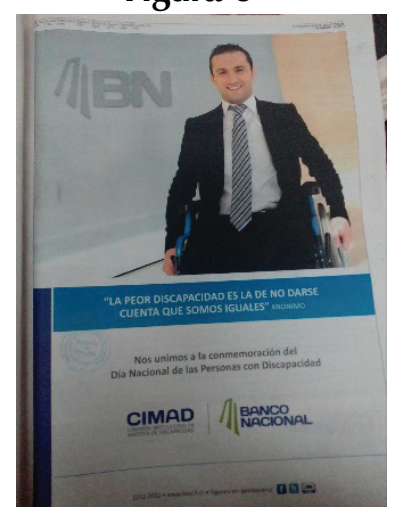

Fuente: LN-031215-P9A
A nivel textual, además de utilizarse para hacer énfasis en las personas con discapacidad, en los anuncios analizados se encontró una recurrencia en la aparición de temas particulares para cada anuncio y aparecían en la ubicación en planos centrales también, normalmente inferiores a las imágenes de PCD. Como se observa en la Figura 5 y en la Figura 6, los lemas "La peor discapacidad es la de no darse cuenta que somos iguales", "Anónimo" y "Luchemos por la igualdad y reconozcamos el esfuerzo de quienes la hacen valer" se ubican en el plano central e, incluso, en la Figura 6, superpuesto a la imagen. 
Aunado a la anterior, es preciso agregar un asunto muy importante para el análisis de los anuncios publicitarios: el realce es un modo en relación intersemiótica que se emplea a lo largo de los anuncios como refuerzo para la creación de significados. Así, por ejemplo, no podemos obviar el empleo de la tipografía en mayúscula, los diferentes tamaños, las comillas, el enmarcado con líneas o en un rectángulo, entre otros, para facilitar la comprensión del receptor (Vergara-Heidke, 2012) del mensaje de los anuncios y reforzar la idea de que los beneficiarios de los anuncios son las PCD. Esto se refuerza con la clara diferencia que hay con la forma y el tratamiento de la frase de gancho y elementos del componente redaccional, ya que estos se refieren directamente al anunciante y tienen el objetivo de exaltar la labor que hace las instituciones emisoras en el anuncio que refieren directamente al anunciante, tal como se profundizará con el modo color.

\subsection{Color}

Como afirman Kress y Van Leeuwen (2001), el color es un modo plurisignificativo y permite crear sentidos propios a lo largo del esquema de color, e incluso se puede hablar de actos de color, según su metafunción del lenguaje. En el caso de los anuncios analizados, las relaciones de color que se establecen son la de representación, con el fin de demarcar la separación de las personas relacionadas o externas al emisor del anuncio, tanto a nivel textual como visual. Sirva de ejemplo la Figura 3, en el que el color blanco del texto (ipodríamos pensar que también a nivel visual?) se relaciona directamente con las personas pertenecientes a la institución, mientras que en amarillo se presenta todo lo vinculado con "discapacidad" textual y visualmente, tal como se muestra en la Figura 7:

Figura 7

\section{Relación de colores}

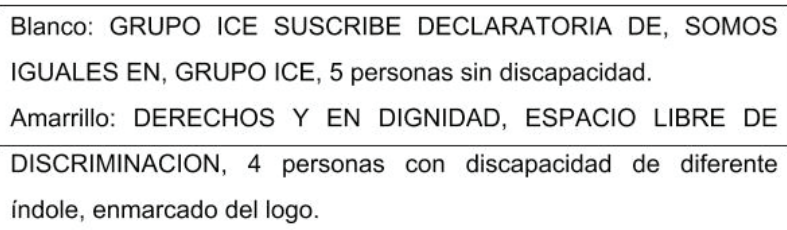

Fuente: DE-291016-P26

Como se puede ver, por un lado, lo suscrito al emisor es de color blanco, está en el centro del logo y muestra el marco legal y de obligatoriedad para la empresa de ser parte del tópico "discapacidad", además de mostrarse como una institución que busca la igualdad. Por otro lado, al adentrarnos en el uso de los colores, se puede observar que todo lo amarillo se separa del emisor y se relaciona con las personas con discapacidad, de modo que se resalta la razón del anuncio: derechos, dignidad, no discriminación. Por lo tanto, relacionando este análisis multimodal, podemos notar que, aunque la institución emisora se presente de una manera, la representación del color permite demostrar que se mantiene la separación de las personas con discapacidad, y que se les relaciona con grupos minoritarios y vulnerables, lo que conlleva a la difusión de estereotipos negativos hacia las PCD.
Figura 8

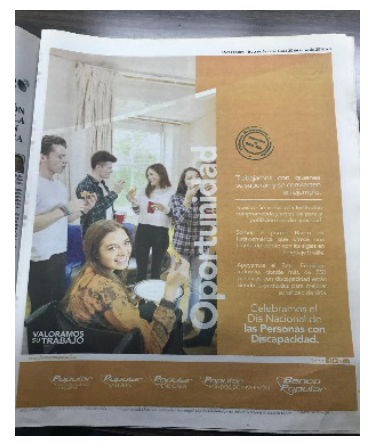

Fuente: DE-110516-P3
Figura 9

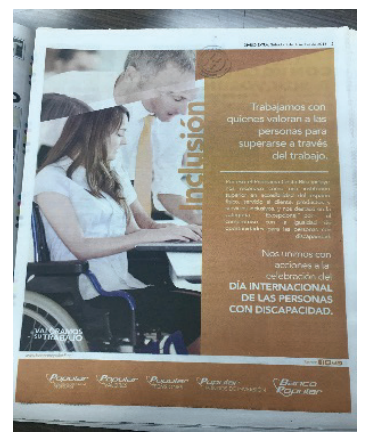

Fuente: DE-110516-P3
Figura 10

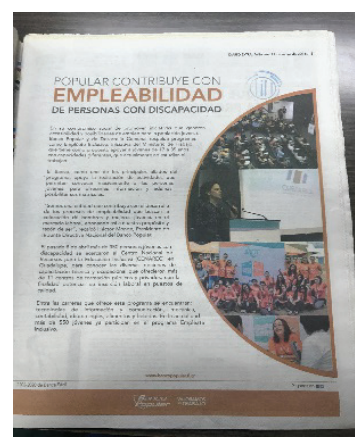

Fuente: DE-300516-P5 
Figura 11

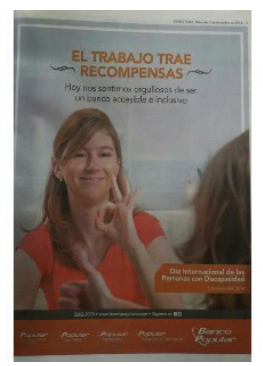

Fuente: DE-031216-P5
Figura 12

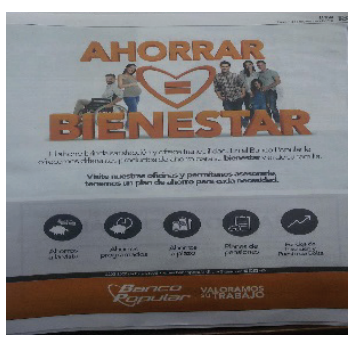

Fuente: DE-031214-P3
Continuando con las metafunciones del color, a nivel interpersonal o de acción, las PCD son desplazadas a funciones pasivas, como se mostró en el apartado anterior, tanto a nivel textual por los roles semánticos poco agentivos en los que se ubican, como por el protagonismo de los elementos relacionados con el emisor en los anuncios, como se ve en las Figuras 6, 8 y 9, en las que todas las PCD están recibiendo una ayuda por parte de otro. En el apartado de representación de los actores sociales se ampliarán estos datos.

Por último, respecto de la identificación, podemos observar que el color tiene la función de identificar a lo largo de varios anuncios publicados en los tres años al emisor, el motivo y la función de la pauta. En las Figuras 6, 8, 9, 10, 11 y 12, en las que los colores blanco y anaranjado, propios del logo del emisor, se emplean para enmarcar e identificar los principios del Banco Popular, emisor del anuncio, "Oportunidad", "Inclusión" y el motivo del anuncio "Día Internacional de las Personas con Discapacidad", "Celebramos el Día de Nacional de las Personas con Discapacidad", en el componente textual, y para identificar a los trabajadores del Banco Popular que brindan ayuda a las PCD (la persona que utiliza LESCO en la Figura 10 y con camiseta anaranjada y la corbata anaranjadas en las Figuras 9 y 6 , respectivamente).

Por tanto, se puede decir que hay un esquema de color según los colores del anunciante que se representa en el vestuario de las personas, el fondo de las fotografías, el enmarcado de los elementos realzados, la fuente de las letras del componente redaccional, entre otros, y que el color tiene fun- ciones de acción, identificación y representación, que permiten denotar la forma en la que las PCD se integran a la sociedad, pero desde una posición obligatoria que muestra asistencialismo, es decir, no se les incluye y no se les presenta de forma independiente, por lo que es una actitud discriminatoria.

\subsection{Enmarcado y encuadre}

Otros modos que se emplean en los anuncios son, aunque en menor medida, el encuadre y podemos decir que los planos y los ángulos tipo close-up -en el que se muestran únicamente los rostros de las personas- se perciben como imágenes no discriminatorias, ya que no muestran la condición discapacitante; las hechas en el plano medio o de cintura, que se divide en aquellas con el ángulo de perfil muestran la condición discapacitante como en la Figura 6, como las que se realizan con ángulo frontal en la Figura 5, que se consideran menos discriminatorias y más inclusivas, ya que no se destaca el carácter "discapacidad" en la persona de la imagen; y las del plano corto, y las que son tomadas en el plano entero y general, que dependen de la distribución y ubicación de los elementos para determinar cuál es el sentido que producen.

Tal como se ha mencionado someramente en el desarrollo de cada modo, la construcción de sentidos en los anuncios se da multimodalmente, pues los modos se relacionan entre sí y dichas relaciones permiten establecer procesos sígnicos de representación y exclusión, inclusión y separación de las personas con discapacidad, los emisores de los anuncios y la sociedad en general. Al hablar de color y podría decirse de un posible realce, por ejemplo, es indispensablemente relacionarlo con la 
tipografía (fuente, tamaño, negrita, cursiva, color), ubicación, enmarcado a nivel textual y con color, vestuario, ubicación, fondo, distribución de los elementos del anuncio, a nivel de imagen.

\section{Representación de las personas con discapaci- dad}

Respecto de la representación de las PCD, el primer criterio de abordaje fue el protagonista de los anuncios y el rol que tiene. Tras el análisis podemos decir que hay un primer punto de crítica; la escasa cantidad de anuncios sobre discapacidad, tal como se ha presentado en Vergara-Heidke y Torres-Calderón (2019), ya que solamente el 0,0015\% de los 42.393 anuncios revisados tiene relación con discapacidad, "lo que muestra la invisibilización que se hace de un grupo poblacional que representa un $10, \%$ de la población costarricense" (p. 20), es decir, casi podría afirmarse que hay una nula representación de las PCD en los anuncios publicitarios de la prensa escrita costarricense en el período analizado.

Siguiendo con esta categoría de análisis, para determinar el protagonismo de los actores sociales, se establece que hubo 114 PCD que aparecieron en los anuncios:

\section{Figura 13 \\ Roles de las personas con discapacidad en el corpus analizado}

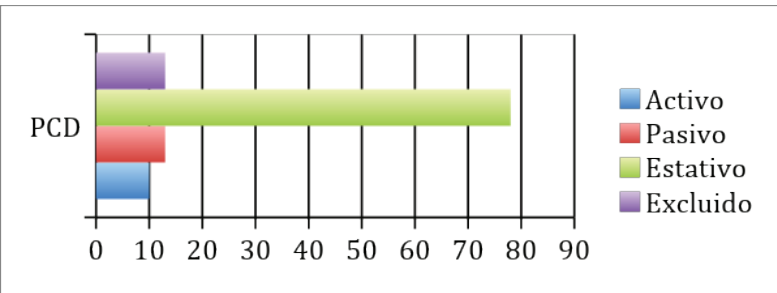

Fuente: elaboración propia

En la Figura 13 se aprecia la distribución de los roles que tienen las PCD en los anuncios publicitarios del 2014 al 2016. Destaca la escasa aparición de estos personajes con roles activos (solamente 10), mientras que los roles menos protagónicos, incluso los de exclusión que son 13, son mayores. Como se observa, el rol estativo es el de mayor aparición (73), es decir, aquel en el que las PCD aparecen posando solamente.
Esta representación de las personas con discapacidad presenta varias ideas sobre las personas y sobre la discapacidad, principalmente, que en la sociedad se les relega a roles menos protagónicos (pasivos, estativos), y que incluso se les excluye. Además, es posible hablar de la existencia de una contradicción ya que, por ejemplo, hay anuncios que buscan, en teoría, ser inclusivos, y cuyo tema se relaciona con las PCD, pero no presentan ninguna imagen alusiva, sin importar el rol que cumpla, aunque se esperaría que fuera activa.

A nivel textual, el protagonismo lo tienen las entidades que pautan los anuncios y se hace mediante la enunciación directa del nombre de la entidad o con el uso de un verbo en primera persona plural con sujeto tácito que refiere a la institución, como en "Hoy nos sentimos orgullosos" en DE-031214-P3 o "Nos unimos" en LN-290314-P7, además de las acciones que se incentivan, por ejemplo: "ACTIVAR", "REPORTE", "DENUNCIAR", "luchemos... reconozcamos", entre otras.

\section{Gráfico 1 \\ Proxémica de los participantes en los anuncios}

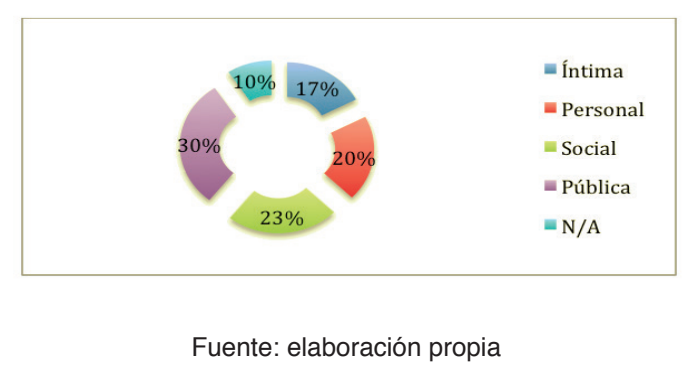

En el segundo criterio de análisis (la relación entre los participantes del anuncio), se determinó si hay relación entre los personajes del anuncio y cuál es la distancia entre ellos. En el caso del primer punto, se emplearon 188 personajes (personas o dibujos) y 80 sí se relacionan ya mediante un abrazo, la simulación de una conversación, un gesto, un apretón de manos, entre otros; mientras que 72 de estos no lo hacen. Precisa añadir que hubo 36 casos en los que no había forma de relacionarse porque la persona aparecía sola en un recuadro o en el anuncio en total o que no había persona en el anuncio. 
De los casos en los que se relacionaban, tal como se muestra en el Gráfico 1, la distancia pública, que es considerada como "la distancia entre personas que son y se mantienen desconocidos" (Kress y Van Leeuwen, 2001, p.125), es la más frecuente con un $33 \%$, seguida de la distancia social $(23 \%)$, la personal (20\%), la íntima (17\%) y destaca en estos datos que la relación "N/A" que representa aquellos anuncios en los que no hay personas o que las personas que aparecen no tienen contacto entre sí pues están en marcos diferentes.

En términos generales, a raíz de este análisis se puede afirmar que, aunque los anuncios en el plano textual hacen referencia a un "nosotros" cercano, visualmente podemos determinar que las personas con discapacidad son desplazadas a roles secundarios (pasivos, estativos y excluidos) y la relación que se establece mediante la información proxémica hace notar que hay una discrepancia entre la forma textual y la imagen mostrada, ya que es más común la separación, la distancia entre las personas que representan al emisor y los objetos que sirven de referencialidad y las PCD.

\section{A MODO DE CIERRE}

A nivel teórico, se revisaron los discursos sobre discapacidad y como primer punto se estableció la diferencia entre el modelo social con una base integracionista y el modelo de diversidad función o inclusivo. Se consideró pertinente hacer la distinción en cuanto a las diferencias discursivas que cada uno de estos dos presenta, por lo que es un primer acercamiento al tema sobre discapacidad desde una perspectiva más amplia que amerita mayor profundización.

Además, se establecieron y caracterizaron los recursos semióticos o modos empleados para difundir la noción de discapacidad presente en los anuncios. Se analizaron las relaciones intersemióticas entre los modos, fundamental para el análisis multimodal y para la construcción de sentidos, pues la ubicación específica de los componentes relacionados con las PCD y el encuadre de estos son los de mayor carga semántica, ya que tienen una función de construcción de sentidos, y que el color tiene fun- ciones lingüísticas de identificación, acción y representación.

En cuanto a la representación de las PCD en los anuncios, del rol que cumplen $y$, por ende, el discurso de discapacidad que se presenta a partir del análisis de las anteriores categorías, se caracteriza porque las PCD son invisibilizadas en el discurso publicitario (68 de 42.5 tienen relación con discapacidad), son diferentes (no filiación con los anunciantes), necesitan ayuda (acciones recibidoras y roles complementarios), son vulnerables (relación con otros grupos minoritarios vulnerables) y se publica sobre el tema por obligatoriedad (derechos, conmemoración, integración, se les puede excluir visualmente).

Por último, a modo de reflexión, tal como lo presenta Madero (2012) en su estudio, es pertinente decir que al ser un discurso de discapacidad altamente discriminatorio y peyorativo, en el que se promueve una imagen negativa de las PCD, es pertinente cuestionarse, en primer lugar, si en el ámbito publicitario las instituciones que pautan solamente están cumpliendo una obligación o realmente se quiere que haya inclusión de todas las personas; $y$, en segundo lugar, plantearse la duda sobre el discurso de discapacidad que se reproduce en los anuncios y el que se quiere para las PCD, ya que dista mucho uno del otro, incluso son contradictorios, por ejemplo, al promover la inclusión mediante las palabras y excluir o evidenciar la diferencia en las imágenes.

\section{REFERENCIAS BIBLIOGRÁFICAS}

Adam, J. M. y Bonhomme, M. (2000). La argumentación publicitaria. Retórica del elogio y de la persuasión. España: CÁTEDRA.

Cebrián, H. M. (2010). Percepción de la imagen de las personas con discapacidad por los profesionales de los medios audiovisuales. Madrid: Fundación ONCE.

Corker, M. (2008). Diferencias, fusiones y bases. ¿Son estos los límites de la representación teórica "precisa" de las experiencias de las personas con discapacidad? En Barton, L. (Comp.), Superar las 
Recursos semióticos en los anuncios publicitarios sobre discapacidad en la prensa escrita costarricense

barreras de la discapacidad (pp. 142-164). Madrid: Ediciones Morata.

Fairclough, N. (2003). Analysing Discourse. Textual analysis for social research. Londres: Routledge.

Fairclough, N. y Wodak, R. (2008). 10. Análisis crítico del discurso. En Van Dijk, T. A. (Comp.). El discurso como interacción social. Estudios sobre el discurso II. Una introducción multidisciplinaria (pp.367-404). Barcelona: Gedisa.

Ferreira, M.A.V. (2008). De la minus-valía a la diversidad funcional: un nuevo marco teóricometodológico. Política y Sociedad, 47 (1), 45-65.

Fernández, D. (2016). Educación de personas con diversidad funcional. Algunos apuntes históricos. Revista de Actualidades Investigativas en Educación. 16 (3), pp.1-23.

Francisco, S. (ed.) (2003). Medios de Comunicación y Discapacidad. Un análisis de la cobertura periodística sobre inclusión social. Brasil: Programa Regional para América Latina y El Caribe.

Gimeno, B. (2008). El discurso de la discapacidad. Revista Trasversales, 12, pp.1-7. Disponible en http://www.trasversales.net/t12bg.htm.

Halliday, M. (1979). El lenguaje como semiótica social. México, D. F.: Fondo de Cultura Económica.

Halliday, M. (2014). An introduction to Functional Grammar. Londres: Arnold.

Jäger, S. (2003). 3. Discurso y conocimiento: aspectos teóricos y metodológicos de la crítica del discurso y del análisis de dispositivos. En Wodak, R. y Meyer, M. (Eds.), Métodos de análisis crítico del discurso (pp.61-99). Barcelona: Editorial Gedisa.

Jewitt, C. (2009). The Routledge Handbook of Multimodal Analysis. Londres/New York: Routledge.

Kress, G. (2009). What is a mode? En Jewitt, C. (Ed.), The Routledge Handbook of Multimodal Analysis (pp. 54-67). New York: Routledge.

Kress, G. (2010). Multimodality: a social semiotic approach to contemporary communication. Nueva York: Routledge.
Kress, G. (2012). Multimodal discourse analysis. En Gee, P. J. y Handord, M. (Eds.), The Routledge Handbook of Discourse Analysis (pp. 35- 50). Londres: Routledge.

Kress, G., y Van Leeuwen, T. (2001). Multimodal Discourse: The Modes and Media of Contemporary Communication. Londres: Arnold.

Kress, G. y Van Leeuwen, T. (2002). Colour as a semiotic mode: notes for a grammar of colour. $\mathrm{Vi}$ sual Communication, 1(3), 343-368.

Kress, G., y Van Leeuwen, T. (2006). Reading images: the grammar of graphic design. Londres: Routledge.

López, G. M. (2006). Modelos teóricos e investigación en el ámbito de la discapacidad. Hacia la incorporación de la experiencia personal. Revista Docencia e Investigación. Escuela Universitaria de Magisterio de Toledo, 16, pp. 215-240.

Madero, G. (2012). Discapacidad en la publicidad. Departamento de Formación, Empleo, DesarroIlo, Igualdad de Oportunidades y Juventud. CastiIla: Consejo Comarcal de Bierzo.

Manghi, D., Arancibia, M., Illanes, O., Letelier, P. y Zamora, M. (2014). Medios semióticos y definiciones multimodales en las clases de Ciencias Naturales y Ciencias Sociales en una escuela para jóvenes sordos. Onomázein (en línea). Disponible en:<http://www.redalyc.org/articulo. oa?id=134532846004 $>$ ISSN 0717-1285.

O'Halloran, K. (2012). Análisis del discurso multimodal. ALED, 12 (1), 75-97.

O'Halloran, K. y Smith, B. A. (s.f.). Multimodal Text Analysis. Disponible en http://multimodal-analysis-lab.org/_docs/encyclopedia/01-Multimodal_ Text_Analysis-O'Halloran_and_Smith.pdf.

OMS. (2011). Informe Mundial sobre la Discapacidad. (2011). Organización Mundial de la Salud. Disponible en www.who.int/iris/bitstre am/10665/75356/1/9789240688230_spa.pdf.

Palacios, A. (2008). El modelo social de discapacidad: orígenes, caracterización y plasmación en la 
Convención Internacional sobre los Derechos de las Personas con Discapacidad. Madrid: Cinca.

Peters, S. (2008). ¿Existe una cultura de la discapacidad? Un sincretismo de tres cosmovisiones posibles. En Barton, L. (Comp.), Superar las barreras de la discapacidad (pp. 142-164). Madrid: Ediciones Morata.

Toboso-Martín, M. (2013). De los discursos actuales sobre la discapacidad en España. Política y Sociedad, 50 (2), 681-706.

Vergara-Heidke, A. (2012). El realce: una propuesta para su conceptualización e identificación. Filología y Lingüística, 38 (2), 163-181.

Vergara-Heidke, A. (2014). El realce: algunos recursos para realizar en textos multimodales. Revista de Filología y Lingüística de la Universidad de Costa Rica, 40 (1), pp. 231-253.
Vergara-Heidke, A. (2018). El discurso sobre la discapacidad: exclusión y auto-exclusión desde las familias de personas con discapacidad. Cadernos de Linguagem e Sociedade, 19(1), 209-231.

Vergara-Heidke, A. y Torres-Calderón, G. (2019). Representación de las personas con discapacidad en los anuncios publicitarios en Costa Rica: revisión desde el análisis multimodal. Logos, Revista de Lingüística, Filosofía y Literatura (29), 1, 149164.

Victoria, M. J. (2013). El modelo social de la discapacidad: una cuestión de Derechos Humanos. Boletín Mexicano de Derecho Comparado, 138, 1093-1109.

Wodak, R. y Meyer, M. (Eds.). (2003). Métodos de análisis crítico del discurso. Barcelona: Editorial Gedisa. 